\title{
A retrospective cohort analysis of ionised calcium levels in major trauma patients who have received early blood product transfusion in the Emergency Department
}

\author{
Stacey J Webster ${ }^{1 *}$, Samuel JH Todd ${ }^{2}$, Chris R Wright ${ }^{3}$ \\ From London Trauma Conference 2014 \\ London, UK. 9-12 December 2014
}

\section{Background}

Exsanguination and coagulopathy remain one of the leading causes of preventable trauma related death [1]. Low ionised calcium levels have been associated with hypotension and increased mortality [2]. Blood product contains citrate that acts as a calcium chelating agent. We hypothesized that trauma patients are at risk of hypocalcaemia and blood products given to resuscitate them would reduce serum Calcium concentration, and therefore affect 30-day mortality.

\section{Methods}

A retrospective cohort analysis was performed on all major trauma patients who had received early blood product in the Emergency Department of a single London Major Trauma Centre over a one year period (January 2013 - January 2014). Ionised calcium levels were taken from venous blood gases from before and after blood product had been transfused. Excel was used to analyse the data.

\section{Results}

The study included 60 patients aged between 10 and 92 (mean 40), 46 male (77\%) and 14 female (23\%). Mechanism of injury was predominantly blunt $48(80 \%)$ and penetrating $12(20 \%)$. Patients received between 1 and 16 units of blood product (mode 2). Mean ISS was 26 (5-50) and overall 30 day mortality was $12 \%$.

$60 \%$ were hypocalcaemic on arrival before receiving any blood product (Mean [Ca] 1.1mmol/L 95\% CI 1.08 - 1.13)

\footnotetext{
* Correspondence: stacey.webster@doctors.org.uk

'Lt, Royal Army Medical Corps; Frimley Health NHS FT

Full list of author information is available at the end of the article
}

$89 \%$ of patients were hypocalcaemic after receiving blood product (Mean $[\mathrm{Ca}] 0.95 \mathrm{mmol} / \mathrm{L} 95 \%$ CI $0.9-1.01$ ). There was a statistically significant difference between ionized calcium levels pre and post blood transfusion. A drop in calcium was seen after receiving just one unit of packed red blood cells, with the average drop being $0.05 \mathrm{mmol} / \mathrm{L}$ per unit of blood product received.

\section{Conclusion}

Trauma patients that have sustained blood loss are at risk of hypocalcaemia. Receiving just one unit of blood product further compounds their hypocalcaemic state and the more units that are given the greater the fall that is seen.

\section{Authors' details}

${ }^{1}$ Lt, Royal Army Medical Corps; Frimley Health NHS FT. ${ }^{2}$ Flt Lt, Royal Air Force Medical Branch; Imperial Healthcare NHS Trust. ${ }^{3}$ Lt Col, Royal Army Medical Corps; Imperial Healthcare NHS Trust.

\section{Published: 11 September 2015}

\section{References}

1. Hess J R, Brohi K, Dutton R P, Hauser C J: The coagulopathy of trauma: a review of mechanisms. Journal of Trauma- ... 2008.

2. Magnotti $L$ J, et al: Admission lonized Calcium Levels Predict the Need for Multiple Transfusions: A Prospective Study of 591 Critically III Trauma Patients. The Journal of Trauma: Injury, Infection, and Critical Care 2011, 70:391-397.

doi:10.1186/1757-7241-23-S2-O3

Cite this article as: Webster et al:: A retrospective cohort analysis of ionised calcium levels in major trauma patients who have received early blood product transfusion in the Emergency Department. Scandinavian Journal of Trauma, Resuscitation and Emergency Medicine 2015 23(Suppl 2):03. 